\title{
Diabetes-related cardiovascular and economic burden in patients hospitalized for heart failure in the US: a recent temporal trend analysis from the National Inpatient Sample
}

\author{
Menatalla Mekhaimar ${ }^{1}$ - Soha Dargham ${ }^{1} \cdot$ Mohamed El-Shazly $^{1} \cdot$ Jassim Al Suwaidi $^{1} \cdot$ Hani Jneid $^{2}$. \\ Charbel Abi Khalil ${ }^{1,3,4}$ (D)
}

Published online: 15 September 2020

(C) The Author(s) 2020

\begin{abstract}
We aimed to study the cardiovascular and economic burden of diabetes mellitus (DM) in patients hospitalized for heart failure (HF) in the US and to assess the recent temporal trend. Data from the National Inpatient Sample were analyzed between 2005 and 2014. The prevalence of DM increased from 40.4 to $46.5 \%$ in patients hospitalized for HF. In patients with HF and DM, mean (SD) age slightly decreased from 71 (13) to 70 (13) years, in which $47.5 \%$ were males in 2005 as compared with $52 \%$ in 2014 ( $p$ trend $<0.001$ for both). Surprisingly, the presence of DM was associated with lower in-hospital mortality risk, even after adjustment for confounders (adjusted OR $=0.844$ (95\% CI [0.828-0.860]). Crude mortality gradually decreased from $2.7 \%$ in 2005 to $2.4 \%$ in 2014 but was still lower than that of non-diabetes patients' mortality on a yearly comparison basis. Hospitalization for HF also decreased from 211 to 188/100,000 hospitalizations. However, median (IQR) LoS slightly increased from 4 (2-6) to 4 (3-7) days, so did total charges/stay that jumped from 15,704 to 26,858 USD (adjusted for inflation, $p$ trend $<$ 0.001 for both). In total, the prevalence of DM is gradually increasing in HF. However, the temporal trend shows that hospitalization and in-hospital mortality are on a descending slope at a cost of an increasing yearly expenditure and length of stay, even to a larger extent than in patient without DM.
\end{abstract}

Keywords Heart failure · Diabetes mellitus · Mortality · Length of stay · Cardiovascular disease

\section{Abbreviations \\ CAD coronary artery disease \\ $\mathrm{HF}$ heart failure \\ $\mathrm{HFpEF}$ heart failure with preserved ejection fraction \\ HFrEF heart failure with reduced ejection fraction \\ ICD International Classification of Diseases \\ LOS length of stay}

Electronic supplementary material The online version of this article (https://doi.org/10.1007/s10741-020-10012-6) contains supplementary material, which is available to authorized users.

Charbel Abi Khalil

cha2022@med.cornell.edu

1 Research Department, Weill Cornell Medicine-Qatar, Doha, Qatar

2 The Michael E. DeBakey VA Medical Centre, Baylor College of Medicine, Houston, TX, USA

3 Joan and Sanford I. Weill Department of Medicine, Weill Cornell Medicine, New York, NY, USA

4 Department of Health Policy, London School of Economics, London, UK
LVEF left ventricular ejection fraction

NIS National Inpatient Sample

\section{Background}

Heart failure (HF) is a rising public health challenge. There are approximately 26 million worldwide suffering from HF, including more than 6.5 million people in the US [1]. HF prevalence increases gradually with age and represents a common cause of hospitalization and re-admissions, especially in the elderly [2]. It is therefore one of the leading causes of morbidity and mortality in CVD behind coronary artery disease (CAD) and stroke [3].

Diabetes mellitus (DM) and HF are often encountered together since they share many cardiovascular risk factors. Up to $40 \%$ of HF patients have DM, a prevalence that even increases more in elderly patients [4]. Several registries have already shown that the presence of DM in the general population is associated with a higher risk of developing HF on the longterm, and the presence of DM in a HF population is associated 
with a higher risk of cardiovascular events and rehospitalizations for $\mathrm{HF}[5,6]$.

During the past decades, cardiovascular medicine has witnessed the emergence of new treatments and the implementation of primary and secondary prevention guidelines and healthcare policies, which was translated into a mortality reduction from CVD [7], in particular from CAD and stroke [8]. However, this gradual improvement in cardiovascular outcome comes at the price of an exponential increase in health expenditure in all CVD medicine specialties $[9,10]$. Despite the ongoing pandemic of heart failure, temporal analysis suggests a reduction in age-specific and cause-specific mortality during the past 2 decades $[11,12]$. We therefore assessed the cardiovascular and economic burden of DM in patients hospitalized for HF and examined its national trend.

\section{Methods}

\section{Data source}

We analyzed data from the National Inpatient Sample (NIS), which is the largest database of in-hospital patients in the US. It is part of the Healthcare Cost and Utilization Project (HCUP), which is financed by the Agency for Healthcare Research and Quality (AHRQ) [13]. Available publicly since the early 2000s till 2016, the NIS contains clinical and economic data pertinent to diagnosis and comorbidities, patients' demographics, hospitals' characteristics, severity and comorbidity measures, procedures, length of stay (LoS), total charges, payment sources and discharge status. There is an average of 7 million admissions collected yearly from over 1000 hospitals in 44 states, representing a stratified $20 \%$ sample of the US population, which forms almost $95 \%$ of all US admissions after weighting. Personal data are deidentified and medical acts/diagnosis are coded using the International Classification of Disease - 9th edition (ICD-9) up till 2014 and ICD-10th edition afterwards.

\section{Diagnosis and outcomes}

The primary diagnosis for this study was hospitalization for HF in patients who are 18 years of age or older (ICD-9 codes: 402.01, 402.11, 402.91, 404.01, 404.03, 404.11, 404.13, 404.91, 404.93, and all 428 sub-groups), and the secondary diagnosis was DM (ICD-9 codes: 250.0 to 250.9 with a fifth digit of 0 or 2). Patients with unknown age, gender, length of stay, in-hospital outcome, and hospital cost were excluded. Cardiovascular outcomes consisted of hospitalization for $\mathrm{HF} / 100,000$ adults and in-hospital mortality. Economic outcomes included length of stay (LoS) and total cost/stay.

\section{Statistical analysis}

Baseline categorical variables and outcome measures are presented using frequency distributions, and means (standard deviations) or medians (interquartile ranges) were used for continuous variables as appropriate. We used a trend test to assess temporal changes. Comparison of HF patients with vs without DM was performed using a Student's $t$ test or a $\chi^{2}$ test. The total number of hospitalizations/year is weighted using a specific software to provide a nationwide estimate per the recommendation of the AHRQ [13], than presented per 100,000 population based on the yearly US population according to the US census bureau (https://www.census.gov). Briefly, patient-level discharge trend weights consisted of applying the DISCWT variable prior to 2012 and the TRENDWT variable from 2012 to 2014. Weighting results in improved national estimates, in addition to allowing for multi-year analysis of trends. In-hospital mortality is presented as crude and then stratified according to gender. Multivariable logistic regression analysis was performed to look for predictors of inhospital mortality in patients with HF and DM. The model included age, gender, comorbidities, race, income, hospital characteristics, and the Charlson/Deyo comorbidity index; the latter being a point-based system with scores ranging from 1 to 6 with each value weighted depending on the prognostic impact of the 22 comorbidities included [14]. A Poisson regression analysis was used to estimate an annual percentage (with its 95\% CI) of change in mortality and outcome. Costs were corrected for inflation using rates provided by the US bureau of labor statistics (https://data.bls.gov/cgi-bin/cpicalc. pl). A $p$ value $<0.05$ was considered statistically significant. Analyses were performed using SPSS (IBM, version 22.0) and STATA (version 15).

\section{Results}

\section{Baseline characteristics of all patients hospitalized with heart failure}

A total of 2,122,415 HF patients hospitalized from 2005 to 2014 were included in our analysis after exclusion of patients with missing records (Fig. 1). After weighting, our study sample consisted of 10,511,776 HF patients: 4,454,833 (43.2\%) with DM and 5,839,543 (56.8\%) without DM.

Baseline characteristics of all patients with HF are shown in Supplementary Table 1 . The absolute number of patients hospitalized with HF in the US gradually increased with time. Mean age (SD) decreased from 73 (14) to 72 (14) years old $(p<0.001)$. The age distribution and sex ratio significantly changed over time: The proportions of patients in the age interval 75 to 84 and $>85$ gradually decreased whereas those of the age intervals $<55,55-64$, and $65-74$ gradually 
Fig. 1 Flow chart of the analysis. $\mathrm{HF}$, heart failure

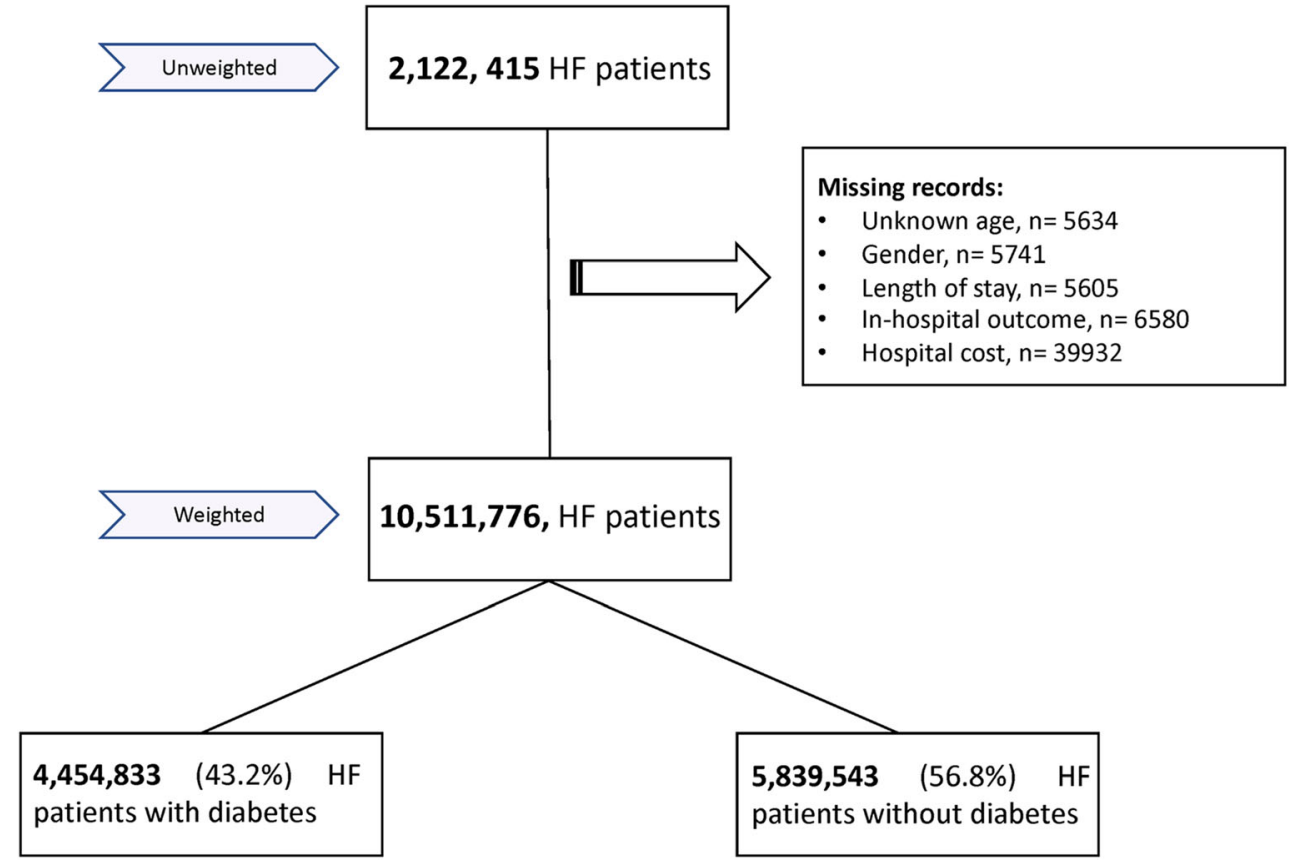

increased ( $p$ trend $<0.001$ for all). In 2005, there were slightly more females (51.9\%), but this trend shifted to the opposite in 2014. The prevalence of DM steadily increased from 40.4 to $46.5 \%$, which represents an absolute increase of $6.1 \%$ in a decade. The prevalence of other risk factors, such as hypertension, CAD, obesity, dyslipidemia, and smoking was also on the rise, which was translated in a temporal increase in Charlson's score over time ( $p$ trend $<0.001$ for all).

A similar temporal trend of age, gender ratio, and risk factors in patients with heart failure and DM and those without DM was observed. In HF patients without DM, mean age (SD) decreased from 71 (13) in 2005 to 70 (13) in 2014 (Table 1), and that of HF patients without DM moved from 74 (15) to 73 (15) (Supplementary Table 2). Cardiometabolic risk factor prevalence was on an ascending slope, so was the prevalence of CVD, such as CAD and renal failure on both groups. Interestingly, the prevalence of White Americans decreased and that of African Americans and Asians increased in diabetic HF with DM, whereas the race distribution was unchanged in HF patients without DM except of a slight increase in the prevalence of Asians.

\section{Temporal trend in cardiovascular outcomes}

We first combined all HF patients with DM for the period of 2005 to 2014, and then compared them to those without DM for the same period. As seen in Table 2, patients with DM and HF were on average 3 years younger, more likely to belong to non-White minority groups, have a lower income, and suffered from more cardio-metabolic risk factors, such as obesity and hypertension. Cardiovascular pathologies, such as CAD and chronic renal failure, were also more prevalent. Surprisingly, the presence of DM was associated with lower in-hospital mortality risk: 111,133 deaths occurred in HF patients with DM (2.5\%) versus 220,745 deaths $(3.8 \%)$ in $\mathrm{HF}$ patients without $\mathrm{DM}, \mathrm{OR}=0.651(95 \%$ CI $[0.641-0.656])$, $p<0.001$. Even after multivariable adjustment on all parameters that were statistically significant between both groups, HF without DM had a lower mortality risk, adjusted $\mathrm{OR}=0.844$ (95\% CI [0.828-0.860]), $p<0.001$.

We looked for predictors of mortality in those patients. As expected, increasing age is associated with higher mortality risk. For instance, patients older than 84 years have a 5 -fold higher risk of dying than those 55 years of age or younger (Table 3). Females are more protected than males, and White Americans have a higher risk than all other ethnic groups. As expected, previous cardiovascular events, such as renal failure, valvular heart disease, or peripheral vascular events - but not coronary artery disease-increased significantly the risk. Interestingly, the presence of cardiometabolic risk factors, such as obesity, hypertension, dyslipidemia, and smoking, had a protective effect.

Furthermore, we compared on a yearly basis the mortality in both groups. Unexpectedly, mortality in HF patients with DM was unexpectedly but sustainability lower from 2005 till 2014.

In HF patients with DM, crude mortality gradually decreased from $2.7 \%$ in 2005 to $2.4 \%$ in 2014 (Supplementary Table 3), which represents an absolute decrease of $0.3 \%$ in 10 years and an annual average decrease of $0.01 \%$ [95\% CI 
Table 1 Baseline characteristics of all patients with HF from 2005 to 2014 , according to the presence of Diabetes

\begin{tabular}{|c|c|c|c|}
\hline Years & $\begin{array}{l}\text { Heart failure patients with } \\
\text { diabetes } \\
N=4,454,833\end{array}$ & $\begin{array}{l}\text { Heart failure patients without } \\
\text { diabetes } \\
N=5,839,542\end{array}$ & $p$ value \\
\hline \multicolumn{4}{|l|}{ Age } \\
\hline Mean (SD) & $71(13)$ & $74(15)$ & $<0.001$ \\
\hline $55-64$ & $835,952(18.8)$ & 680,201 (11.6) & $<0.001$ \\
\hline $65-74$ & $1,176,474(26.4)$ & $961,190(16.5)$ & $<0.001$ \\
\hline $75-84$ & $1,262,978(28.4)$ & $1,659,077(28.4)$ & $<0.001$ \\
\hline$>84$ & $645,476(14.5)$ & $1,756,911(30.1)$ & $<0.001$ \\
\hline \multicolumn{4}{|l|}{ Gender } \\
\hline Male & $2,221,535$ (49.9) & $2,883,926(49.4)$ & $<0.001$ \\
\hline Female & $2,233,299(50.1)$ & $2,955,617$ (50.6) & $<0.001$ \\
\hline \multicolumn{4}{|l|}{ Race } \\
\hline White & $2,411,597(63.1)$ & $3,508,611(71.6)$ & $<0.001$ \\
\hline Black & $823,586(21.5)$ & $905,400(18.5)$ & $<0.001$ \\
\hline Hispanic & $386,624(10.1)$ & $285,625(5.8)$ & $<0.001$ \\
\hline Asian & $76,382(2)$ & 70,737 (1.4) & $<0.001$ \\
\hline Native American & $25,370(0.7)$ & $23,135(0.5)$ & $<0.001$ \\
\hline Other & $98,976(2.6)$ & $103,419(2.1)$ & $<0.001$ \\
\hline \multicolumn{4}{|l|}{ Income } \\
\hline Low & $1,546,020(35.5)$ & $1,831,534(32)$ & $<0.001$ \\
\hline Low-mid & $1,162,972(26.7)$ & $1,517,262(26.6)$ & $<0.001$ \\
\hline High-mid & $955,262(21.9)$ & $1,289,277(22.6)$ & $<0.001$ \\
\hline High & $692,360(15.9)$ & $1,076,649(18.8)$ & $<0.001$ \\
\hline \multicolumn{4}{|l|}{ Insurance } \\
\hline Medicare & $3,288,992(74)$ & $4,405,484(75.6)$ & $<0.001$ \\
\hline Medicaid & $389,579(8.8)$ & $423,920(7.3)$ & $<0.001$ \\
\hline Private insurance & $556,756(12.5)$ & $670,562(11.5)$ & $<0.001$ \\
\hline Self-pay & $122,096(2.7)$ & $207,756(3.6)$ & $<0.001$ \\
\hline No charge & $12,877(0.3)$ & $20,553(0.4)$ & $<0.001$ \\
\hline Other & $77,262(1.7)$ & $100,639(1.7)$ & $<0.001$ \\
\hline \multicolumn{4}{|l|}{ Comorbidity } \\
\hline Obesity & $944,309(21.2)$ & $544,572(9.3)$ & $<0.001$ \\
\hline Hypertension & $3,150,266(70.7)$ & $3,513,841(60.2)$ & $<0.001$ \\
\hline Smoking & $182,820(20.3)$ & $250,695(21.3)$ & $<0.001$ \\
\hline Dyslipidemia & $399,759(44.4)$ & $363,226(30.8)$ & $<0.001$ \\
\hline \multicolumn{4}{|l|}{ Past medical history } \\
\hline PVD & $580,847(13)$ & $531,775(9.1)$ & $<0.001$ \\
\hline $\begin{array}{l}\text { Valvular heart } \\
\text { disease }\end{array}$ & $14,116(0.3)$ & $20,171(0.3)$ & $<0.001$ \\
\hline Renal failure & $1,955,821(43.9)$ & $1,790,252(30.7)$ & $<0.001$ \\
\hline CAD & $474,232(52.7)$ & $491,700(41.7)$ & $<0.001$ \\
\hline \multicolumn{4}{|l|}{ Hospital bedsize } \\
\hline Small & $590,696(14.8)$ & $804,526(15.6)$ & $<0.001$ \\
\hline Medium & $1,014,278(25.5)$ & $1,302,158(25.3)$ & $<0.001$ \\
\hline Large & $2,379,740(59.7)$ & $3,043,215(59.1)$ & $<0.001$ \\
\hline \multicolumn{4}{|l|}{ Hospital location } \\
\hline Rural & $600,356(15.1)$ & $798,911(15.5)$ & $<0.001$ \\
\hline Urban & $3,384,358(84.9)$ & $4,350,988(84.5)$ & $<0.001$ \\
\hline \multicolumn{4}{|l|}{ Hospital region } \\
\hline Northeast & $799,758(20)$ & $1,091,333(21.1)$ & $<0.001$ \\
\hline
\end{tabular}


Table 1 (continued)

\begin{tabular}{llll}
\hline Years & $\begin{array}{l}\text { Heart failure patients with } \\
\text { diabetes } \\
N=4,454,833\end{array}$ & $\begin{array}{l}\text { Heart failure patients without } \\
\text { diabetes } \\
N=5,839,542\end{array}$ & $p$ value \\
\hline Midwest & $945,667(23.6)$ & $1,218,489(23.6)$ & $<0.001$ \\
South & $1,696,082(42.4)$ & $2,113,830(40.9)$ & $<0.001$ \\
West & $562,024(14)$ & $750,059(14.5)$ & $<0.001$ \\
Charlson score & & & $<0.001$ \\
0 & $8771(1)$ & $274,150(23.3)$ & $<0.001$ \\
1 & $164,377(18.3)$ & $439,192(37.3)$ & $<0.001$ \\
2 & $293,598(32.6)$ & $284,231(24.1)$ & $<0.001$ \\
$\geq 3$ & $432,676(48.1)$ & $181,327(15.4)$ & \\
\hline
\end{tabular}

PVD, peripheral vascular disease; CAD, coronary artery disease

$(0.001 ; 0.02)](p=0.039)$. The reduction was observed in men ( $2.8 \%$ in 2005 to $2.5 \%$ in 2014 ) and women (2.7\% in 2005 to $2.4 \%$ in 2014) ( $p$ trend $<0.001$ for all) (Fig. 2a).

Mortality in HF patients without DM followed the same trend. Crude mortality gradually decreased from $4.5 \%$ in 2005 to $3.4 \%$ in 2014 , which represents an absolute decrease of $1.1 \%$ during this same decade and an annual average decrease of $0.063 \%$ [95\% CI $(0.052 ; 0.073)](p<0.001)$. The reduction was observed in men (4.4\% in 2005 in 2005 to $3.3 \%$ in 2014) and women ( $4.6 \%$ in 2005 to $3.4 \%$ in 2014) ( $p$ trend $<0.001$ for all).

Interestingly, there was a gender effect according to the presence of DM. In HF patients without DM, women had a higher mortality risk from 2005 up till $2010(p<0.001)$, but no statistically significant difference in mortality is seen afterwards. In HF with DM patients, men had a higher mortality risk at all years except in 2006, 2007, and 2001 when the statistical significance was not reached, which confirmed the results of our multivariable regression analysis.

Furthermore, we performed a yearly multivariable regression analysis on all cofounding variables. Interestingly, the presence of DM was consistently associated with lower inhospital mortality despite all adjustments from 2005 to 2014 (Fig. 2b).

Hospitalization for HF decreased from 211/100,000 adults in 2005 to $188 / 100,000$ adults in 2014 ( $p$ trend $<0.001$ ) (Fig. 3a). A similar significant trend was also observed in patients without DM.

\section{Temporal trend in economic outcomes of patients with heart failure and DM}

Total charges gradually increased with time: In patients with DM, charges went from 15,704 $(9127-29,400)$ to reach 26,858 (15,638-48,590) USD/stay (adjusted for inflation, $p$ trend $<0.001$ ), which represents a mean annual increase of $5.9 \%$ (95\% CI [5.4-6.5], $p<0.001$ ). In HF without DM, the inflation-adjusted cost/stay also increased from 15,745 (8912$31,043)$ to $24,770(14,421-45,071)$ USD (adjusted for inflation, $p$ trend $<0.001$ ), which represents a mean annual increase of $4.9 \%$ (95\% CI [4.4-5.2], $p<0.001$ ) (Fig. 3b). Of note, total charges were significantly higher in patients with DM on a yearly basis $(p<0.01)$.

The LoS was significantly lower in non-diabetic HF patients from 2005 to 2014 on a yearly basis (Supplementary Table 4). There was a slight temporal reduction in the LoS of non-diabetic HF patients from 4 (2-7) days in 2005 to 4 (2$6)$ days in 2014. However, the LoS slightly increased in patients with DM from 4 (2-6) to 4 (3-7) days, $(p$ trend $<0.001$ for both).

\section{Discussion}

We first report in this analysis of the NIS that the prevalence of DM is gradually increasing in patients hospitalized for HF. The prevalence and incidence of DM are increasing in the general population and in individuals with previously established CVD. In a similar analysis of the NIS, Ahmed et al. reported a similar $7 \%$ absolute increase in the prevalence of DM in patients hospitalized for myocardial infarction between 2000 and 2010 [15]. Our data are also aligned with a recent temporal analysis of a large UK cohort, reporting a large increase in the prevalence of DM in HF (18\% in early 2000 s versus $26 \%$ in recent years) [16].

Contrary to our expectations, DM was associated with a reduced in-hospital mortality in HF despite the adjustment for confounders. Studies that reported short-term outcome in patients with HF and DM showed paradoxical results. In the OPTIMIZE-HF registry, one of the earliest and largest US performance-improvement programs in patients hospitalized with HF, in-hospital mortality did not differ according to the presence of baseline DM [17]. Similar findings were recently reported in the Scottish registry that included over 3 million 


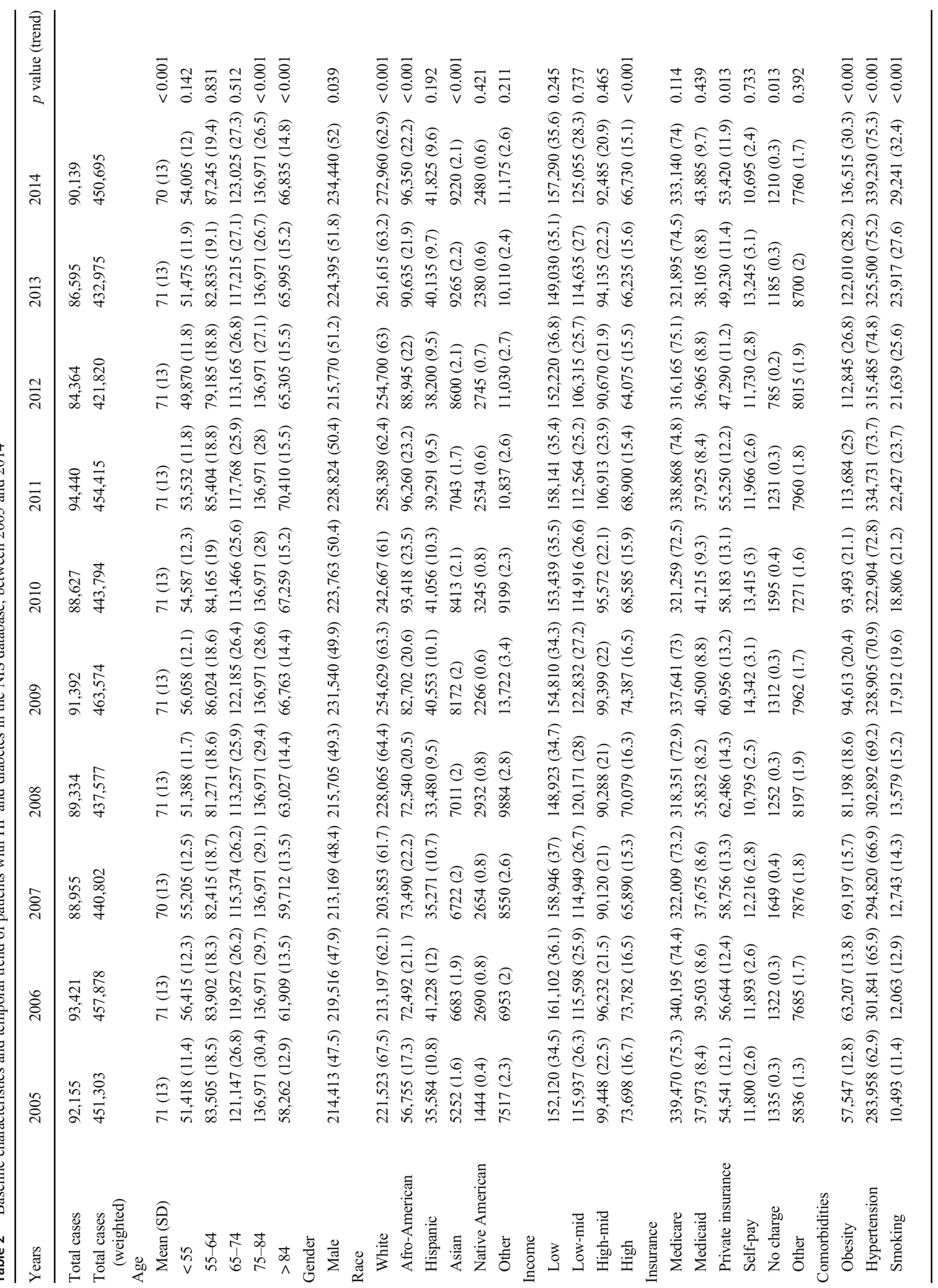




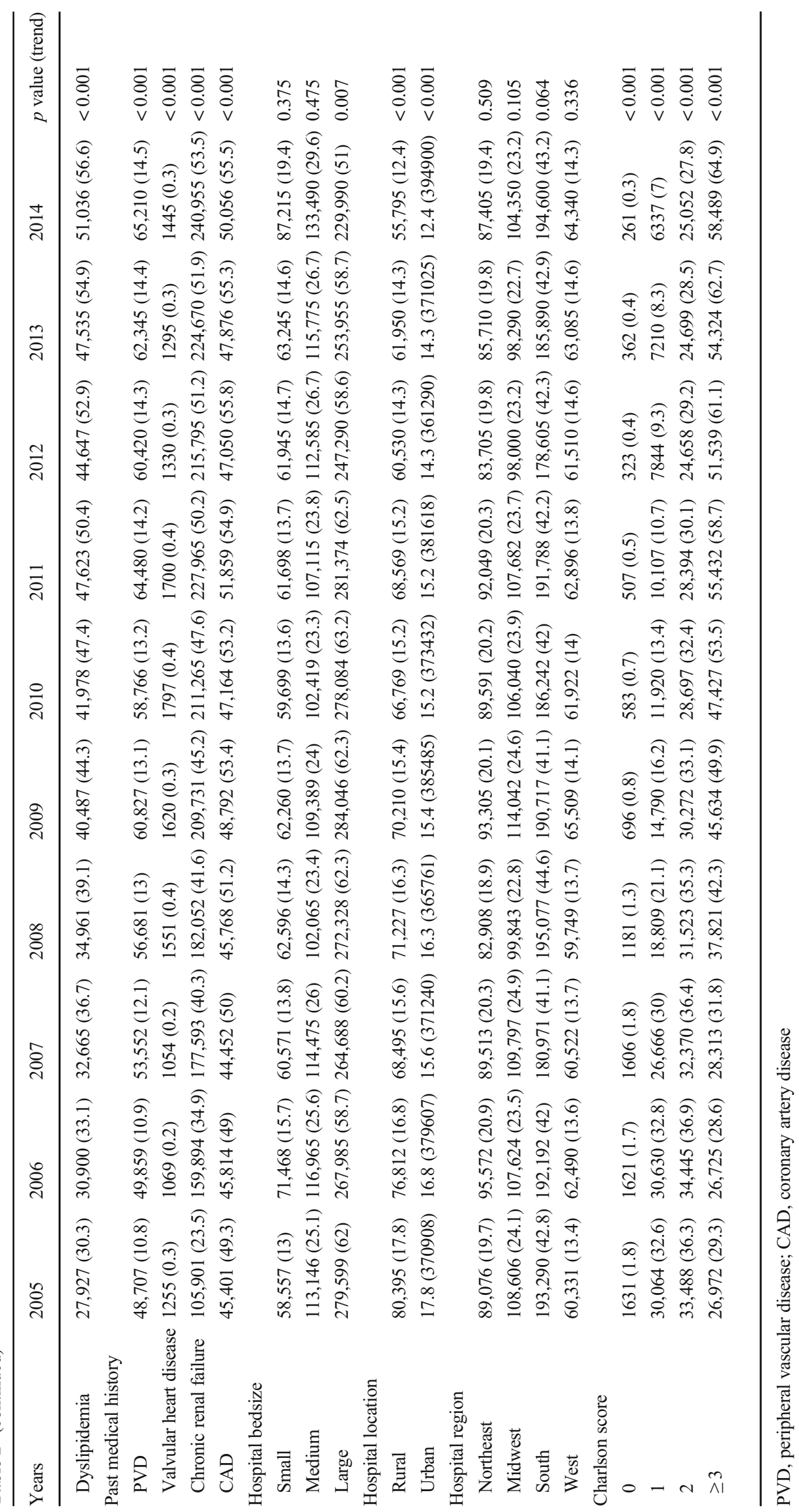


Table 3 Factors associated with in-hospital death in patients with HF and diabetes

\begin{tabular}{|c|c|c|c|}
\hline Years & OR & $95 \% \mathrm{CI}$ & $p$ value \\
\hline \multicolumn{4}{|l|}{ Age } \\
\hline$<55$ & 1 & Referent group & - \\
\hline $55-64$ & 1.394 & 1.349 to 1.441 & $<0.001$ \\
\hline $65-74$ & 2.117 & 2.054 to 2.182 & $<0.001$ \\
\hline $75-84$ & 3.307 & 3.212 to 3.404 & $<0.001$ \\
\hline$>84$ & 5.16 & 5.01 to 5.316 & $<0.001$ \\
\hline \multicolumn{4}{|l|}{ Gender } \\
\hline Male & 1 & Referent group & - \\
\hline Female & 0.952 & 0.84 to 0.963 & $<0.001$ \\
\hline \multicolumn{4}{|l|}{ Race } \\
\hline White & 1 & Referent group & - \\
\hline Black & 0.477 & 0.468 to 0.487 & $<0.001$ \\
\hline Hispanic & 0.688 & 0.673 to 0.705 & $<0.001$ \\
\hline Asian & 0.947 & 0.907 to 0.989 & 0.015 \\
\hline Native American & 0.612 & 0.558 to 0.671 & $<0.001$ \\
\hline \multicolumn{4}{|l|}{ Comorbidity } \\
\hline Obesity & 0.603 & 0.593 to 0.613 & $<0.001$ \\
\hline HTN & 0.678 & 0.670 to 0.686 & $<0.001$ \\
\hline Dyslipidemia & 0.581 & 0.573 to 0.588 & $<0.001$ \\
\hline Smoking & 0.596 & 0.586 to 0.607 & $<0.001$ \\
\hline \multicolumn{4}{|l|}{ Past medical history } \\
\hline PVD & 1.193 & 1.173 to 1.213 & $<0.001$ \\
\hline Valvular heart disease & 2.839 & 2.657 to 3.033 & $<0.001$ \\
\hline Chronic renal failure & 1.476 & 1.458 to 1.494 & $<0.001$ \\
\hline CAD & 0.877 & 0.867 to 0.887 & $<0.001$ \\
\hline \multicolumn{4}{|l|}{ Hospital bedsize } \\
\hline Small & 1 & Referent group & - \\
\hline Medium & 0.928 & 0.910 to 0.946 & $<0.001$ \\
\hline Large & 0.960 & 0.944 to 0.977 & $<0.001$ \\
\hline \multicolumn{4}{|l|}{ Hospital location } \\
\hline Rural & 1 & Referent group & - \\
\hline Urban & 0.898 & 0.884 to 0.913 & 0.001 \\
\hline \multicolumn{4}{|l|}{ Hospital region } \\
\hline Northeast & 1 & Referent group & - \\
\hline Midwest & 0.889 & 0.873 to 0.905 & $<0.001$ \\
\hline South & 0.520 & 0.496 to 0.545 & $<0.001$ \\
\hline West & 0.536 & 0.512 to 0.561 & $<0.001$ \\
\hline
\end{tabular}

PVD, peripheral vascular disease; $\mathrm{CAD}$, coronary artery disease

participants who were followed up until 10 years [18]. Interestingly, a different larger Scottish cohort of over 110,000 HF patients reported a decreased 30-day mortality in patients with DM knowing that in-hospital mortality was not registered [19]. Concordant to our findings, a Spanish registry for over 14 years of follow-up reported a decreased in-hospital mortality in HF patients with DM [20]. Similarly, in the American "Get with the Guidelines-HF Registry," a reduced mortality in patients hospitalized for heart failure was attributed to DM [21]. However, several other cohorts, such as the European Heart Failure registry, reported an increased risk of in-hospital death in the presence of DM [22]. Despite the existence of conflictual data in short-term outcome of patients with $\mathrm{HF}$ and DM, it is well known that the long-term of those patients is poor. In the Swedish National Diabetes Register, hospitalization rates in HF patients with DM were almost 50\% higher as compared with the general population [23]. One year mortality and hospitalization for HF was significantly higher in HF and DM, included in the European Heart Failure registry [22].

It is not known why patients with HF and DM have a better in-hospital outcome in terms of mortality in our cohort. In our study, patients with DM have a higher prevalence of cardiometabolic parameters, such as obesity, hypertension, and renal failure. Therefore, it is highly likely that heart failure with preserved ejection fraction $(\mathrm{HFpEF})$ is more prevalent than heart failure with reduced ejection fraction (HFrEF) in hospitalized, diabetic HF patients knowing that the classification into HFpEF and HFrEF was missing in the NIS before 2010. Furthermore, the composition of HF entities may have changed over time as the HFpEF's proportion within all HF patients has recently changed in the general population and overcame that of HFrEF [24]. One of the plausible mechanisms of decreased mortality in diabetic HF patients could also be the longer LoS that probably leads to more medical acts, procedures, exploratory secondary diagnostics, and targeted treatment, which led to mortality reduction at the price of higher financial costs.

Several reports of "diabetes paradox" exist in the literature. For instance, Krinsley et al. reported that the presence of DM does not increase the risk of in-hospital death in severely ill patients admitted to the intensive care unit [25]. An obesity paradox also governs the relation between DM and mortality. Costanzo et al. showed in a large British cohort that being overweight was associated with a lower mortality risk and being obese does not increase the mortality risk as compared with average-weight individuals with DM [26]. We have recently showed that overweight, obese, and even severe obese HF patients with DM have a better short-term prognosis [27], a finding that we just confirmed in our multivariable analysis. Moreover, some of the classically harmful cardiometabolic parameters of DM, such as hypertension, dyslipidemia, and smoking, were associated with improved outcome in our study, findings that were also reported in previous NIS studies that assesses the impact of DM on other cardiovascular diseases, such as myocardial infarction [15]. One of the plausible mechanisms behind those paradoxical findings is that those patients usually receive more cardioprotective drugs that are known to decrease mortality, a factor that we could not account for in our regression model due to the absence of baseline medications in the NIS registry. 

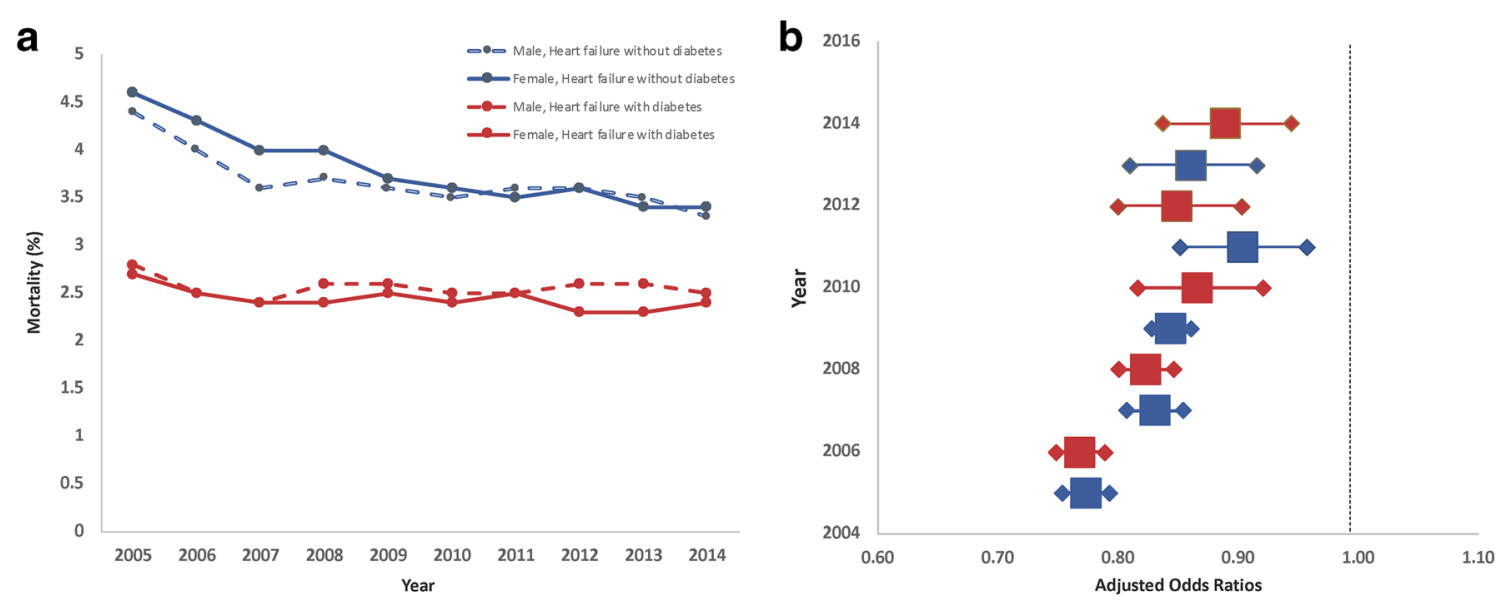

Fig. 2 (a) Mortality trend in patients in patients with heart failure and diabetes (red color) and without diabetes (blue color) according to gender distribution. (b) Boxes represent yearly adjusted odds ratios of mortality (with its $95 \% \mathrm{CI}$ ) in patients with heart failure and diabetes

To our knowledge, we are the first to report that patients with $\mathrm{HF}$ and DM exert an additional cost to the healthcare system. However, our results are concordant with several reports that highlighted the financial burden of DM and its cardiovascular complications. Nichols et al. reported earlier that patients with CVD and DM are more costly than those without $\mathrm{DM}$, in particular at the early course of DM [28]. Aligned with those findings, a recent systematic review that included 24 studies reported that the presence of CVD in patients with DM increased costs by $42 \%$ [29].

The temporal trend in the rate of hospitalization for $\mathrm{HF}$ and its associated mortality risk is concordant with current bibliography pertinent to trends and patterns of CVD and cardiovascular complications of DM in particular. In a similar analysis of the NIS, absolute risk of in-hospital mortality in patients with myocardial infraction and DM was reduced by almost 4\% [15]. Burrows et al. reported a significant annual decrease of cardiovascular-related hospitalizations in patients with DM: $4.6 \%$ in patients with acute coronary syndrome, $3.6 \%$ in patients with HF, and $2 \%$ in ischemic strokes [30]. Of note, similar trends were also reported in the absence of DM.

The increasing cost of healthcare causes an enormous financial pressure on governments and funding agencies worldwide. For instance, the total cost of DM, including its comorbidities and cardiovascular complications, was estimated to be 237 billion USD in 2017, which represents a $26 \%$ increase in 5 years only [10]. According to the American Heart Association, total HF costs are expected to increase by more than twice from 2012 to 2030 [9]. As GLP-1 agonists and SGLT-2 inhibitors were only recently included in DM guidelines, we therefore anticipate a continuous reduction in DM-
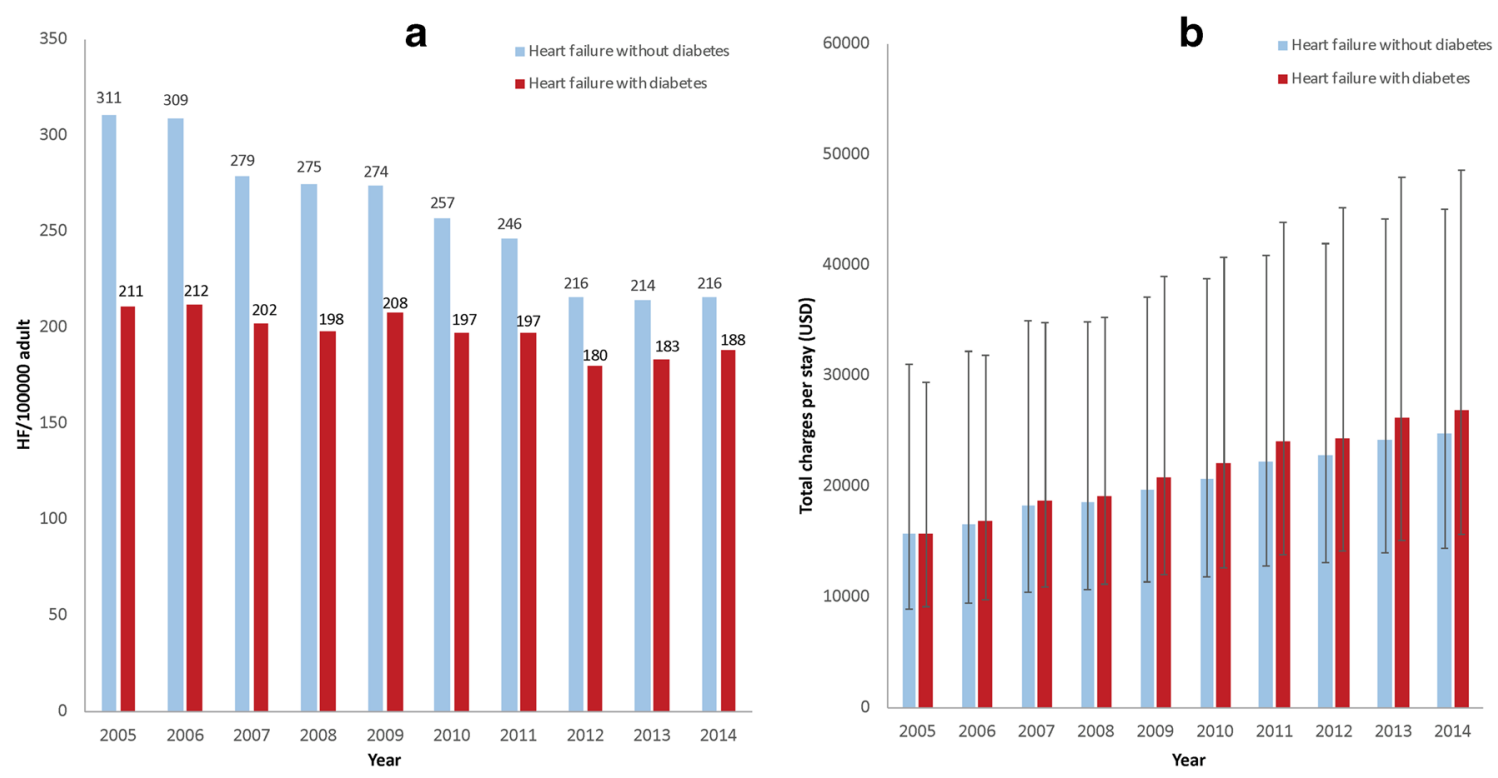

Fig. 3 (a) Trend of heart failure hospitalization/100,000 US adults in patients with diabetes (red color) and without diabetes (blue color). (b) Temporal change in total charges/stay (median $\pm \mathrm{IQR}$ ) in heart failure patients with diabetes (red) and without diabetes (blue) 
related mortality and hospitalization, in particular in patients with $\mathrm{HF}$ since the mortality reduction in those medications was mainly driven by a reduction in HF. We anticipate that newer medications and technologies in DM and HF will result in further mortality reduction given the constant evolution of medical research in cardiovascular disease. However, we also expect a continuous increase in the cost of diabetes-related complications. In fact, aging of the population which is the main driver behind the steady increase in the prevalence of CVD has been traditionally seen as the main contributor to the growing health care expenditure [31]. However, recent data indicate that advances in technologies and price growth contribute even more to healthcare spending, independently of the aging [32].

We acknowledge the presence of several limitations in this study. The NIS is an administrative database which is far from being able to generate a firm conclusion in the absence of randomization. Furthermore, a lot of the variables were not recorded. For instance, many of the mortality predictors in patients with DM and HF are missing, such as the glycemic control $\left(\mathrm{HBA}_{1 \mathrm{c}}\right), \mathrm{LVEF}$, and medications. It is well known that mortality positively correlates with $\mathrm{HBA}_{1 \mathrm{C}}[33]$ — a marker of poor glycemic control - and LVEF and decreases with some medications, such as beta-blockers and ACE-inhibitor/ angiotensin receptor blockers (ARBs) [34]. The inclusion of those variables into our regression models might have influenced the outcome. Furthermore, it was not possible to assess readmission of the same patients knowing that this outcome is one of the most important cardiovascular and economic objectives sought after in HF predictive medicine [35]. Finally, our data analysis stopped at 2014 due to the transition of ICD9 to ICD-10 coding in 2015 in the US and the still-ongoing resulting issues in statistical decoding of the pathologies and analysis; hence, our results might not reflect accurately the trend of HF and DM in the past 5 years.

\section{Conclusion}

The temporal trend shows that the rates of hospitalization and in-hospital mortality are on a descending slope in HF, irrespective of the presence of diabetes mellitus. However, this is counteracted by a continuous rise in the prevalence of DM and an increase in medical expenditure, notably in patients with DM who represent an additional economic burden on the growing cost of heart failure by costing more than their non-diabetic counterparts on a yearly basis.

Acknowledgments The lead author would like to thank Huseyin Naci, $\mathrm{PhD}$, for his guidance and help.

Funding Open Access funding provided by the Qatar National Library.
Availability of data and material Available upon reasonable request from the correspondent author.

\section{Compliance with ethical standards}

Conflict of interest The authors declare that they have no conflict of interest.

Ethics approval The study went through an administrative review only since it did not meet the definition of research involving human subjects given the nature of de-identified data per our institutional review board (IRB), determination letter number 18-00017.

Consent to participate Not applicable.

Consent for publication Not applicable.

Open Access This article is licensed under a Creative Commons Attribution 4.0 International License, which permits use, sharing, adaptation, distribution and reproduction in any medium or format, as long as you give appropriate credit to the original author(s) and the source, provide a link to the Creative Commons licence, and indicate if changes were made. The images or other third party material in this article are included in the article's Creative Commons licence, unless indicated otherwise in a credit line to the material. If material is not included in the article's Creative Commons licence and your intended use is not permitted by statutory regulation or exceeds the permitted use, you will need to obtain permission directly from the copyright holder. To view a copy of this licence, visit http://creativecommons.org/licenses/by/4.0/.

\section{References}

1. Virani SS, Alonso A, Benjamin EJ, Bittencourt MS, Callaway CW, Carson AP, Chamberlain AM, Chang AR, Cheng S, Delling FN, Djousse L, Elkind MSV, Ferguson JF, Fornage M, Khan SS, Kissela BM, Knutson KL, Kwan TW, Lackland DT, Lewis TT, Lichtman JH, Longenecker CT, Loop MS, Lutsey PL, Martin SS, Matsushita K, Moran AE, Mussolino ME, Perak AM, Rosamond WD, Roth GA, Sampson UKA, Satou GM, Schroeder EB, Shah SH, Shay CM, Spartano NL, Stokes A, Tirschwell DL, VanWagner LB, Tsao CW, American Heart Association Council on E, Prevention Statistics C, Stroke Statistics S (2020) Heart disease and stroke statistics - 2020 update: a report from the American Heart Association. Circulation 141(9):e139-e596. https://doi.org/ 10.1161/CIR.0000000000000757

2. Lazzarini V, Mentz RJ, Fiuzat M, Metra M, O'Connor CM (2013) Heart failure in elderly patients: distinctive features and unresolved issues. Eur J Heart Fail 15(7):717-723. https://doi.org/10.1093/ eurjhf/hft028

3. Roth GA, Huffman MD, Moran AE, Feigin V, Mensah GA, Naghavi M, Murray CJ (2015) Global and regional patterns in cardiovascular mortality from 1990 to 2013. Circulation 132(17): 1667-1678. https://doi.org/10.1161/CIRCULATIONAHA.114. 008720

4. Thrainsdottir IS, Aspelund T, Thorgeirsson G, Gudnason V, Hardarson T, Malmberg K, Sigurdsson G, Ryden L (2005) The association between glucose abnormalities and heart failure in the population-based Reykjavik study. Diabetes Care 28(3):612-616. https://doi.org/10.2337/diacare.28.3.612

5. Nichols GA, Gullion CM, Koro CE, Ephross SA, Brown JB (2004) The incidence of congestive heart failure in type 2 diabetes: an 
update. Diabetes Care 27(8):1879-1884. https://doi.org/10.2337/ diacare.27.8.1879

6. Cavender MA, Steg PG, Smith SC Jr, Eagle K, Ohman EM, Goto S, Kuder J, Im K, Wilson PW, Bhatt DL, Investigators RR (2015) Impact of diabetes mellitus on hospitalization for heart failure, cardiovascular events, and death: outcomes at 4 years from the reduction of Atherothrombosis for Continued Health (REACH) registry. Circulation 132(10):923-931. https://doi.org/10.1161/ CIRCULATIONAHA.114.014796

7. Wadhera RK (2017) Cardiovascular medicine amid evolving health policy: time to train a generation of policy leaders. J Am Coll Cardiol 70(17):2201-2204. https://doi.org/10.1016/j.jacc.2017.09. 017

8. Mensah GA, Wei GS, Sorlie PD, Fine LJ, Rosenberg Y, Kaufmann PG, Mussolino ME, Hsu LL, Addou E, Engelgau MM, Gordon D (2017) Decline in cardiovascular mortality: possible causes and implications. Circ Res 120(2):366-380. https://doi.org/10.1161/ CIRCRESAHA.116.309115

9. Heidenreich PA, Albert NM, Allen LA, Bluemke DA, Butler J, Fonarow GC, Ikonomidis JS, Khavjou O, Konstam MA, Maddox TM, Nichol G, Pham M, Pina IL, Trogdon JG, American Heart Association Advocacy Coordinating C, Council on Arteriosclerosis T, Vascular B, Council on Cardiovascular R, Intervention, Council on Clinical C, Council on E, Prevention, Stroke C (2013) Forecasting the impact of heart failure in the United States: a policy statement from the American Heart Association. Circ Heart Fail 6(3):606-619. https://doi.org/10. 1161/HHF.0b013e318291329a

10. American Diabetes A (2018) Economic costs of diabetes in the U.S. in 2017. Diabetes Care 41(5):917-928. https://doi.org/10.2337/ dci18-0007

11. Conrad N, Judge A, Canoy D, Tran J, Pinho-Gomes AC, Millett ERC, Salimi-Khorshidi G, Cleland JG, McMurray JJV, Rahimi K (2019) Temporal trends and patterns in mortality after incident heart failure: a longitudinal analysis of 86000 individuals. JAMA Cardiol 4:1102-1111. https://doi.org/10.1001/jamacardio.2019.3593

12. Vasan RS, Zuo Y, Kalesan B (2019) Divergent temporal trends in morbidity and mortality related to heart failure and atrial fibrillation: age, sex, race, and geographic differences in the United States, 1991-2015. J Am Heart Assoc 8(8):e010756. https://doi.org/10. 1161/JAHA.118.010756

13. National Inpatient Sample (NIS) Healthcare Cost and Utilization Project (HCUP). Agency for Healthcare Research and Quality, Rockville https://www.hcup-us.ahrq.gov/nisoverview.jsp. Accessed 10/10/2019

14. Deyo RA, Cherkin DC, Ciol MA (1992) Adapting a clinical comorbidity index for use with ICD-9-CM administrative databases. J Clin Epidemiol 45(6):613-619. https://doi.org/10.1016/08954356(92)90133-8

15. Ahmed B, Davis HT, Laskey WK (2014) In-hospital mortality among patients with type 2 diabetes mellitus and acute myocardial infarction: results from the national inpatient sample, 2000-2010. J Am Heart Assoc 3(4). https://doi.org/10.1161/JAHA.114.001090

16. Conrad N, Judge A, Tran J, Mohseni H, Hedgecott D, Crespillo AP, Allison M, Hemingway H, Cleland JG, McMurray JJV, Rahimi K (2018) Temporal trends and patterns in heart failure incidence: a population-based study of 4 million individuals. Lancet 391(10120):572-580. https://doi.org/10.1016/S0140-6736(17) 32520-5

17. Greenberg BH, Abraham WT, Albert NM, Chiswell K, Clare R, Stough WG, Gheorghiade M, O'Connor CM, Sun JL, Yancy CW, Young JB, Fonarow GC (2007) Influence of diabetes on characteristics and outcomes in patients hospitalized with heart failure: a report from the organized program to initiate lifesaving treatment in hospitalized patients with heart failure (OPTIMIZE-HF). Am
Heart J 154(2) 277:e271-e278. https://doi.org/10.1016/j.ahj.2007. 05.001

18. McAllister DA, Read SH, Kerssens J, Livingstone S, McGurnaghan S, Jhund P, Petrie J, Sattar N, Fischbacher C, Kristensen SL, McMurray J, Colhoun HM, Wild SH (2018) Incidence of hospitalization for heart failure and case-fatality among 3.25 million people with and without diabetes mellitus. Circulation 138(24):2774-2786. https://doi.org/10.1161/ CIRCULATIONAHA.118.034986

19. Kim HL, Kim MA, Park KT, Choi DJ, Han S, Jeon ES, Cho MC, Kim JJ, Yoo BS, Shin MS, Kang SM, Chae SC, Ryu KH, Kor HFR (2019) Gender difference in the impact of coexisting diabetes mellitus on long-term clinical outcome in people with heart failure: a report from the Korean Heart Failure registry. Diabet Med 36: 1312-1318. https://doi.org/10.1111/dme.14059

20. Munoz-Rivas N, Jimenez-Garcia R, Mendez-Bailon M, Hernandez-Barrera V, de Miguel-Diez J, Lorenzo-Villalba N, de Miguel-Yanes JM, Lopez-de-Andres A (2019) Type 2 diabetes increases the risk of hospital admission for heart failure and reduces the risk of in hospital mortality in Spain (2001-2015). Eur J Intern Med 59:53-59. https://doi.org/10.1016/j.ejim.2018.08.011

21. Echouffo-Tcheugui JB, Xu H, DeVore AD, Schulte PJ, Butler J, Yancy CW, Bhatt DL, Hernandez AF, Heidenreich PA, Fonarow GC (2016) Temporal trends and factors associated with diabetes mellitus among patients hospitalized with heart failure: findings from get with the guidelines-heart failure registry. Am Heart J 182:9-20. https://doi.org/10.1016/j.ahj.2016.07.025

22. Targher G, Dauriz M, Laroche C, Temporelli PL, Hassanein M, Seferovic PM, Drozdz J, Ferrari R, Anker S, Coats A, Filippatos G, Crespo-Leiro MG, Mebazaa A, Piepoli MF, Maggioni AP, Tavazzi L, investigators E-HHL-TR (2017) In-hospital and 1-year mortality associated with diabetes in patients with acute heart failure: results from the ESC-HFA heart failure long-term registry. Eur J Heart Fail 19(1):54-65. https://doi.org/10.1002/ejhf.679

23. Rawshani A, Rawshani A, Franzen S, Sattar N, Eliasson B, Svensson AM, Zethelius B, Miftaraj M, McGuire DK, Rosengren A, Gudbjornsdottir S (2018) Risk factors, mortality, and cardiovascular outcomes in patients with type 2 diabetes. N Engl J Med 379(7):633-644. https://doi.org/10.1056/NEJMoa1800256

24. Steinberg BA, Zhao X, Heidenreich PA, Peterson ED, Bhatt DL, Cannon CP, Hernandez AF, Fonarow GC, Get With the Guidelines Scientific Advisory C, Investigators (2012) Trends in patients hospitalized with heart failure and preserved left ventricular ejection fraction: prevalence, therapies, and outcomes. Circulation 126(1): 65-75. https://doi.org/10.1161/CIRCULATIONAHA.111.080770

25. Krinsley JS, Fisher M (2012) The diabetes paradox: diabetes is not independently associated with mortality in critically ill patients. Hosp Pract (1995) 40(2):31-35. https://doi.org/10.3810/hp.2012. 04.967

26. Costanzo P, Cleland JG, Pellicori P, Clark AL, Hepburn D, Kilpatrick ES, Perrone-Filardi P, Zhang J, Atkin SL (2015) The obesity paradox in type 2 diabetes mellitus: relationship of body mass index to prognosis: a cohort study. Ann Intern Med 162(9): 610-618. https://doi.org/10.7326/M14-1551

27. Abi Khalil C, Sulaiman K, Singh R, Jayyousi A, Asaad N, AlHabib KF, Alsheikh-Ali A, Al-Jarallah M, Bulbanat B, AlMahmeed W, Dargham S, Ridha M, Bazargani N, Amin H, Al-Motarreb A, AlFaleh H, Elasfar A, Panduranga P, Al Suwaidi J (2017) BMI is inversely correlated to the risk of mortality in patients with type 2 diabetes hospitalized for acute heart failure: findings from the Gulf aCute heArt failuRE (Gulf-CARE) registry. Int J Cardiol 241:262269. https://doi.org/10.1016/j.ijcard.2017.02.119

28. Nichols GA, Brown JB (2002) The impact of cardiovascular disease on medical care costs in subjects with and without type 2 diabetes. Diabetes Care 25(3):482-486. https://doi.org/10.2337/ diacare.25.3.482 
29. Einarson TR, Acs A, Ludwig C, Panton UH (2018) Economic burden of cardiovascular disease in type 2 diabetes: a systematic review. Value Health 21(7):881-890. https://doi.org/10.1016/j.jval. 2017.12.019

30. Burrows NR, Li Y, Gregg EW, Geiss LS (2018) Declining rates of hospitalization for selected cardiovascular disease conditions among adults aged $>/=35$ years with diagnosed diabetes, U.S., 1998-2014. Diabetes Care 41(2):293-302. https://doi.org/10.2337/ dc17-1259

31. de Meijer C, Wouterse B, Polder J, Koopmanschap M (2013) The effect of population aging on health expenditure growth: a critical review. Eur J Ageing 10(4):353-361. https://doi.org/10.1007/ s10433-013-0280-x

32. Jayawardana S, Cylus J, Mossialos E (2019) It's not ageing, stupid: why population ageing won't bankrupt health systems. Eur Heart J Qual Care Clin Outcomes 5(3):195-201. https://doi.org/10.1093/ ehjqcco/qcz022
33. Iribarren C, Karter AJ, Go AS, Ferrara A, Liu JY, Sidney S, Selby JV (2001) Glycemic control and heart failure among adult patients with diabetes. Circulation 103(22):2668-2673. https://doi.org/10. 1161/01.cir.103.22.2668

34. Abi Khalil C, Al Suwaidi J, Singh R, Asaad N, Abushahba G, Kunju U, Al Qahtani A, AlBinali HA (2017) Beta-blockers are associated with decreased in-hospital mortality and stroke in acute decompensated heart failure: findings from a retrospective analysis of a 22-year registry in the Middle East (1991-2013). Curr Vasc Pharmacol 15(1):77-83

35. Desai AS, Stevenson LW (2012) Rehospitalization for heart failure: predict or prevent? Circulation 126(4):501-506. https://doi.org/10. 1161/CIRCULATIONAHA.112.125435

Publisher's note Springer Nature remains neutral with regard to jurisdictional claims in published maps and institutional affiliations. 